\title{
Effects of Volume Overload and Current Techniques for the Assessment of Fluid Status in Patients with Renal Disease
}

\author{
Can Ekinci $^{\mathrm{a}}$ Merve Karabork $^{\mathrm{a}} \quad$ Dimitrie Siriopol $^{\mathrm{b}}$ Neris Dincer ${ }^{\mathrm{c}}$ \\ Adrian Covic $^{b}$ Mehmet Kanbay ${ }^{d}$

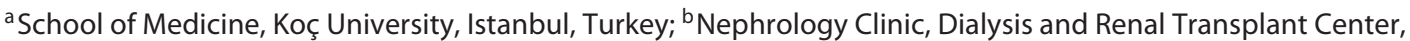 \\ "C.I. PARHON" University Hospital, and "Grigore T. Popa" University of Medicine lasi, lasi, Romania; 'Koc University

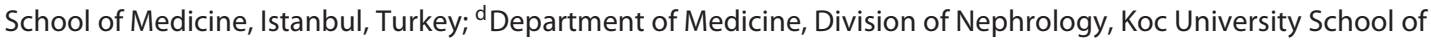 \\ Medicine, Istanbul, Turkey
}

\section{Keywords}

Volume overload · Bioimpedance · Lung ultrasonography

\begin{abstract}
Volume overload is an important, may be the foremost, independent prognostic factor determining the outcome of hemodialysis patients. Therefore, it is crucial to measure fluid status of these patients and avoid volume overload. This review aims to evaluate volume overload, its effects on patients with renal diseases and current methodologies measuring volume status in the body. These techniques will be first classified as clinical evaluation and non-clinical and/or instrumental techniques, which includes biomarkers, ultrasonography, relative blood volume monitoring, bioimpedance, echocardiography, pulmonary artery catheterization, esophageal and/or suprasternal Doppler, and blood viscosity. Advantages and limitations of these different techniques will be reviewed extensively by comparing each other. At last, insights gained from this review can highlight the future prospects in this active area of research.

(c) 2018 S. Karger AG, Basel
\end{abstract}

\section{Introduction}

Volume overload is a very important prognostic factor, associated with impaired oxygenation [1], end-organ damage [2], prolonged hospital stay [3], morbidity [2], and mortality [4], perhaps being one of the most insidious and common risk factor for mortality $[5,6]$ in chronic kidney disease and end-stage renal disease (ESRD) patients. It manifests itself as left ventricular hypertrophy, hypertension, fluid shift into the third space, and increased arterial stiffness. It is also known that chronic kidney disease is an independent risk factor for cardiovascular diseases. In the United States, 38\% of all deaths in dialysis patients are from cardiovascular causes specifically due to arrhythmia and cardiac arrest (24.3\%) [7], which are associated with left ventricular hypertrophy [8] and hypertension [9-11]. Furthermore, among 350,000 ESRD patients, about 280,000 acute episodes per year were due to fluid overload of which more than $80 \%$ required hospitalization costing around USD 1.7 billion annually [12$15]$.

\section{KARGER}

(c) 2018 S. Karger AG, Basel

E-Mail karger@karger.com

www.karger.com/bpu
Mehmet Kanbay, MD

School of Medicine, Koç University School of Medicine

Rumelifeneri Yolu

TR-34450 Sariyer, Istanbul (Turkey)

E-Mail mkanbay@ku.edu.tr, drkanbay@yahoo.com 
In dialysis patients, volume overload is the most common cause of hypertension and may independently contribute to poor cardiovascular outcomes; hydration status and increased mortality are associated independently in ESRD patients $[6,16,17]$. Controlling volume overload is one of the measures that successfully help to manage blood pressure (BP) without the use of antihypertensive medications in $90 \%$ of patients undergoing hemodialysis [18]; in addition, it could benefit the overall health of these patients. This review discusses the effects of volume overload and current techniques for the assessment of fluid status in patients with kidney disease.

There are different methods to measure volume overload with each method having its strengths and limitations. These methods consist of clinical evaluation followed by objective non-clinical/instrumental methods. The most utilized objective methods are evaluation of biomarkers (BNP, pro-BNP and ANP), ultrasonographic findings (inferior vena cava [IVC] collapse index, lung ultrasonography [LUS], carotid artery Doppler, relative blood volume $[\mathrm{RBV}]$ ) monitoring, and bioimpedance (single-/multiple-frequency and segmental/whole body approaches). There are also some other objective methods less commonly used such as: measuring left atrial volume via echocardiography, pulmonary artery catheterization (PAC), measuring aortic flow time via esophageal Doppler monitoring/suprasternal Doppler, and measuring blood viscosity such as cone plane viscometer. PAC, despite its invasiveness and limited usage, is shown to be a reliable guide to assess the volume status and reorganize the therapy in the intensive care unit [19].

It is becoming more common to use these different methods not only for research purposes but also in daily practice in order to improve the assessment of patients' fluid status. Therefore, we aim to critically analyze the upsides and downsides of these different methods used in volume overload monitoring.

\section{Clinical Evaluation of Volume Overload}

\section{Dry Weight}

The earliest volume overload dry weight evaluation was based on clinical measurements, since technological devices and laboratory values were not available or readily reachable. BP measurements were one of the most reliable physical exam findings. Thomson et al. [20] defined dry weight as "reduction of BP to hypotensive levels dur- ing ultrafiltration and unassociated with other obvious causes". Henderson et al. [21] promoted the idea of using intradialytic BP measurements to reach dry weight by stating that "the weight obtained at the conclusion of a regular dialysis treatment below which the patient more often than not will become symptomatic and go into shock". Therefore, although there are some other methods such as percussion of abdomen, auscultation of lungs, heart rate changes - the most used methods in clinical evaluation are BP monitoring (pre, post, and intradialysis or 24-h ambulatory monitoring) and weight measurement.

Today, the dry weight concept is almost unchanged, while the methods used to define it evolved immensely due to the necessity to introduce standardization and reproducibility - that is, a more objective approach. Despite a plethora of new methods, subjective clinical examination still remains as the standard of care for fluid management [22]. BP measurement is still the most widely used method to adjust dry weight today, though it is highly subjective. Notably, there is still not an accepted normal BP level among the medical community. Furthermore, BP readings can be affected by a multitude of factors, including one of the most commonly recognized influences - the white coat anxiety. To get a small change in vital signs (BP and pulse), there should be quite large changes in volume status $[23,24]$. Most importantly, with BP measurements, we can only assess intravascular excess volume, whereas with some instrumental techniques such as bioimpedance analysis, we can also measure excess extravascular volume. Weight measurement is also not a very objective method, since any weight gained might also be due to increased caloric intake. Even a change in the body composition (muscle and fat compositions) may affect the outcome.

Despite all these setbacks, in the most recent metaanalysis, it is shown that although with bioimpedance analysis we can evaluate high BP readings and arterial stiffness more accurately than with classical methods (mainly weight gain measurement), there is still no difference in mortality between one of the most promising methods today, the bioimpedance analysis and the classical methods. However, as the meta-analysis indicated, such negative results may be explained by the overall small sample size [25]. Although there are few studies comparing other objective methods (BNP [26], Carotid artery Doppler [27]) with classical methods, further studies with larger sample sizes are needed to establish a significant outcome (Table 1). 


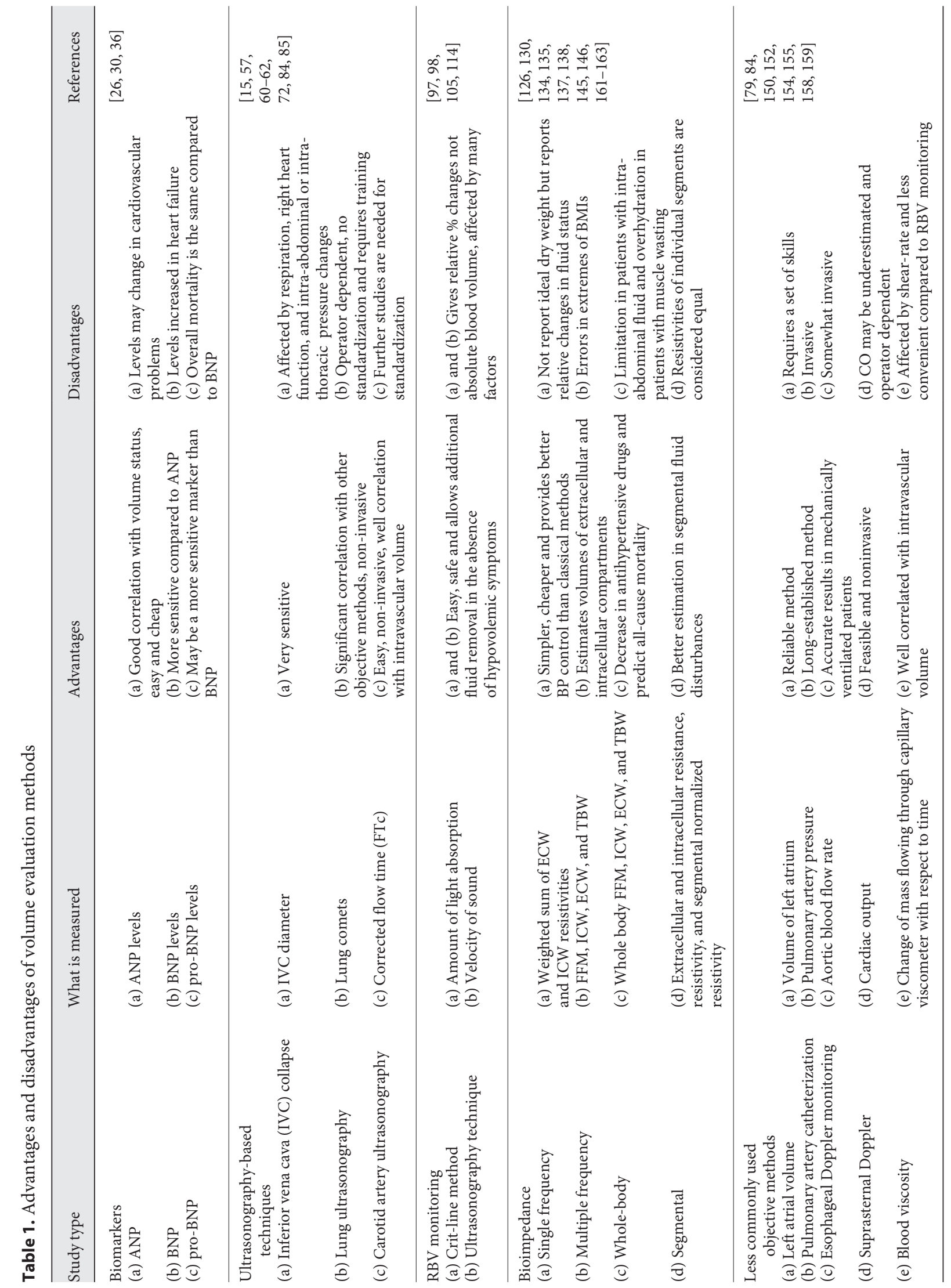




\section{More Objective Techniques to Assess Volume Overload}

\section{Biomarkers (BNP, Pro-BNP, and ANP)}

Atrial natriuretic peptide (ANP) is a hormone released from atria in response to atrial stretch. ANP levels are increased in heart failure and its levels closely correlate with atrial volume. Since ANP is released due to atrial stretch, its levels may also change in some cardiovascular problems. Therefore, a more specific marker, brain natriuretic peptide (BNP), was proposed to assess the volume status.

BNP was first identified in the brain but is primarily released from the heart, particularly by the ventricles [28]. $\mathrm{BNP}$ is produced by the cleavage of the prohormone proBNP. As already mentioned, BNP and ANP levels are increased in heart failure particularly in response to high ventricular filling pressures [29], but even in the absence of a clinically diagnosed heart failure, both ANP and BNP levels are increased in patients with renal insufficiency [30-33]. In these patients, an increase in natriuretic peptides levels was suggested to be a result of either volume expansion or left ventricular hypertrophy [33]. Although the use of natriuretic peptides for fluid status assessment is under debate $[30,34]$, numerous studies show a direct association between these biomarkers and overhydration $[35,36]$, and more importantly with adverse outcomes in ESRD patients [36, 37].

In a recently published study, it was found that while there is a strong relationship between BNP levels and both volume status and survival in hemodialysis patients, there was no clear relation for ANP, thereby making BNP superior to ANP [36]. Another study investigating the superiority between $\mathrm{BNP}$ and pro-BNP suggested that pro$\mathrm{BNP}$ was a more sensitive marker than BNP in the detection of cardiovascular events in hemodialysis patients, although overall cardiac-related mortality did not differ between pro-BNP and BNP [26].

\section{Limitations}

Although BNP and pro-BNP seem to be superior to ANP and could even have a good relationship with volume status and survival in ESRD patients, they are not very specific markers, since their levels are affected by different conditions. Starting from a very early study, it is shown that despite restoration to the normovolemia, BNP levels were not reduced to their normal levels [38]. Other studies showed that, aside cardiovascular conditions, BNP levels can also be affected by some neurologic conditions like hemorrhagic stroke [39] and ischemic stroke [40], by critical illnesses like sepsis [41, 42] and HIV [43], by some pul- monary diseases like pulmonary hypertension $[44,45]$ and pulmonary embolism [46, 47]; or by some other conditions like anemia [48, 49], cirrhosis [50], and hypertension [51]. Moreover, in hemodialysis patients, the levels of natriuretic peptides also seem to be related to the dialytic membranes. Therefore, although using natriuretic peptides, particularly pro-BNP and BNP, to assess volume overload is relatively cheap, due to their relatively low specificity, more studies are needed to clarify their validity to assess volume overload in ESRD patients.

\section{Ultrasonography}

\section{IVC Diameter}

IVC acts as a reservoir for the blood inside the vessels as most of the intravascular volume resides within the venous system. Therefore, changes in the volume status correlate with IVC diameter to some extent with some other additional factors. IVC diameter is affected by respiration [52], blood volume [53], and right heart function [54]. Takata et al. [55] also showed that the IVC diameter is altered by the relation between extra-mural pressure, which is mainly comprised of intra-abdominal pressure and intra-mural pressure, which is close to right atrial pressure, at the level of diaphragm. Therefore, it was shown that one other parameter altering IVC diameter was intra-abdominal pressure.

IVC collapse can be detected by ultrasound, and IVC collapse index (IVCCI) is the proportion that IVC collapses with respiration and can be calculated by (IVCCI $=$ $\left.\left[\mathrm{IVC}_{\max }-\mathrm{IVC}_{\min }\right] / \mathrm{IVC}_{\max }\right)$ [56] or in a different way. Barbier et al. [57] calculated the distensibility index of IVC $\left(\right.$ dIVC) as $\left(D_{\max }-D_{\min }\right) / D_{\min } \times 100$. Changes in collapsibility or distensibility correlate with the fluid status in the body. Therefore, with these formulas, fluid status in children [58], patients who are ventilated $[57,59]$, and healthy patients $[60,61]$ can be calculated.

Although there are studies including a recent one showing that after a certain threshold for dIVC, it is very specific and sensitive for observing volume expansion [57], its validity is still questionable since IVC diameter does not only depend on volume status but also it may be affected by respiration, right heart function, and intraabdominal or intra-thoracic pressure changes. It is also shown that IVC imaging can be challenging especially in patients with large body habitus, excessive bowel gas, or large amounts of intra-thoracic air [62]. Furthermore, since ultrasonographic findings are highly conductor-dependent, results might change between doctors or techni- 
cians. There are studies suggesting that IVC ultrasonography may give false results depending on the approaches taken by the conductor. They state that the axis of collapse [63] and the level of collapse [64] should be determined carefully since it may change the outcome. Another study emphasizing the subjectivity of IVC ultrasonography was recently published and they showed that real-time dynamic changes in limb impedance was capable of tracking the changes in dVIC whose ultrasonography was performed by the team members with special ultrasound training and credentialing [65]. Therefore, they suggested that relatively more objective methods like bioimpedance analysis may be used in the assessment of volume status [63-65]. Muller et al. [65] found that high variations in IVC diameter are associated with fluid responsiveness, but low variations do not exclude the fluid responsiveness emphasizing that the results should be interpreted carefully. On the other hand, Juhl-Olsen et al. [66] did not find any change in IVC diameter in patients before and after the donation of blood. Since there are recent studies showing the high sensitivity and specificity of ultrasonographic evaluation of IVC collapse, it is definitely worth performing further investigations to clarify its effectiveness. Although many factors may affect IVC collapse measurement, it can be used for the assessment of fluid responsiveness where bioimpedance is not available.

\section{Lung Ultrasonography}

LUS is a recent technique that is increasingly used to estimate the amount of extravascular lung water (EVLW), which is commonly seen in patients with heart disease [67] and patients with acute respiratory failure [68].

The presence of EVLW is detected by sending US beams, which will be reflected by the thickened intralobular septa with a consecutive hyperechoic reverberation artifacts generation between the edematous septa and the overlying pleura [6]. These acoustic reverberations will be identified visually as B-lines (formerly known as "lung comets" [69]), which are the equivalent of B-lines (Kerley B-lines) detected by chest X-rays [70]. The extent of pulmonary congestion can be assessed by the number and strength of these comets $[6,15,71-73]$. Although in ESRD the relationship between EVLW, as assessed by LUS, and different markers of volume status is still uncertain [74], there is a clear relationship between EVLW and different adverse outcomes in this population. Zoccali et al. [6] first showed that the degree of lung congestion was a better predictor for mortality, cardiovascular events, and hospi- talization than the assessment done by the NYHA score, and that it could even improve prediction for mortality but not cardiovascular events. Later, these results were confirmed by Siriopol et al. [75], which showed that lung US was associated with prediction of survival even after the adjustments for echocardiographic and bioimpedance parameters, whereas this technique is not able to improve risk prediction for all-cause mortality in hemodialysis patients beyond classical and echocardiographicbased risk prediction scores/parameters [76].

There is only one published randomized trial (the BUST study) that investigated the use of LUS for treatment guiding in HD patients. There was no difference between the 2 groups (active and control) with regard to the primary composite outcome (all-cause mortality and $\mathrm{CV}$ events) or secondary outcomes (all-cause mortality, CV events, hospitalizations, or vascular access thrombosis). However, the authors found an increased rate ratio for intradialytic cramps, but a lower rate ratio for predialytic dyspnea in patients in the active group [74].

\section{Limitations}

Overall, although most studies support LUS as a novel and easy-to-use technique, there are studies questioning its usefulness and objectivity [77]. The B-lines have limited specificity, as it is difficult to differentiate between fibrotic B-lines (related to thickening of sub-pleural intralobular or interlobular septa, like in systemic sclerosis) and edematous B-lines [69]. Furthermore, it is also difficult to differentiate between EVLW accumulation secondary to heart failure or respiratory disease [78]. This technique can also be inaccurate in patients with morbid obesity, subcutaneous emphysema, pneumectomy, or pleurisy.

\section{Carotid Artery - Corrected Flow Time}

Since the rapid evaluation and fluid management are very important in critically ill patients, different techniques have been developed to optimize the fluid resuscitation therapy. One of the earliest methods was PAC, which has been used for almost half of a century especially in emergency departments and intensive care units $[79,80]$. However, since this method was inconvenient, time-consuming and invasive, innovative techniques like ultrasound evaluation started to replace the PAC. Studies with esophageal Doppler (ED) to detect changes in aortic flow time suggested a value in interpretation of volume status. However, these studies also indicated that ED was
38

Blood Purif 2018;46:34-47 DOI: $10.1159 / 000487702$
Ekinci/Karabork/Siriopol/Dincer/Covic/ Kanbay 
still somewhat invasive, almost only applicable for intubated patients and required great experience, which also made it quite subjective [81-83]. Due to aforementioned reasons, using carotid artery (CA) as a substitute seemed feasible, since the CA is slightly distal to the aorta by providing very similar characteristics to the CA. Also, since $\mathrm{CA}$ is more superficial, evaluation requires less experience compared to ED or other methods like echocardiography and it was easier to perform in severely ill patients highlighting its value in the emergency situations $[84,85]$.

Corrected flow time (FTc), flow time/ $\sqrt{\text { cycle time, cal- }}$ culated by considering heart rate correction is used to evaluate intravascular volume status and FTc was found to be directly correlated with intravascular volume by different studies [27, 84-87]. Blehar et al. [84] and Hilbert et al. [86] showed that FTc was increased after intravascular volume expansion. Blehar et al. [84] also indicated that after fluid administration, although there was a significant change in FTc, there were no changes in mean arterial pressure or heart rate emphasizing the value of using FTc. Although Mackenzie et al. [85] studied on blood donors, Hossein-Nejad et al. [27] included hemodialysis patients in their study and both studies found a significant relationship showing decreased FTc in response to loss of intravascular volume. Hossein-Nejad et al. [27] also indicated that decrease in FTc was significant in both groups of patients with or without a history of anti-hypertensive drug use. A study done by Stolz et al. [88] to investigate the applicability of Doppler to measure common CA velocity time integral, which is a novel another method for potential use in assessing volume responsiveness, was performed in emergency settings by emergency residents from a single institution to assess volume status. They found that there were no differences between novice and experienced groups to perform key elements of the examination with a success greater than $75 \%$. Therefore, they indicated that common carotid Doppler flow measurement is a valuable technique due to several merits especially in the emergency settings [88].

Marik et al. [89] evaluated FTc after a passive leg raise maneuver, which is suggested to deliver around $300 \mathrm{~mL}$ blood to central circulation noninvasively, without fluid administration. They concluded that changes in FTc following passive leg raise might be a novel method for evaluating fluid responsiveness in hemodynamically unstable patients [89]. Similarly, Shokoohi et al. [87] found a significant change in FTc after passive leg raise maneuver in a sample of dehydrated patients in fasting state. In contrast, this relationship was not significant in a study recently done by Peachey et al. [90]. They indicated that while there was a fall in IVCCI, and increase in stroke volume and cardiac output, no significant change was observed in carotid Doppler velocity suggesting a possible superiority of IVCCI evaluation over CA Doppler [90]. However, they also concluded that since they did not measure the CA diameter by assuming no change would be present with passive leg raise, results might be representing a false negative finding; another possible explanation was that they performed the carotid Doppler velocity measurement at the end of their protocol, raising the possibility that effects of passive leg raise maneuver might have already disappeared [90].

Although there are some contradictions, most of the literature supports the use of CA Doppler especially in the emergency settings at which it will probably provide the maximum benefit. However, since this is a brand new technique, there are some limitations restricting its validity. First and foremost, there is a need for a study investigating the normal values and cutoff points of FTc indicating a volume responsiveness in a normal population, since there is no study present about this matter yet. Also, since this is a brand new technique, more studies should be performed to see its applications not just in emergency departments but within all units of the hospitals in which fluid management is important.

\section{Blood Volume Monitoring}

Blood volume monitoring (BVM), which has been around a century now [91], is another method proposed to estimate dry weight through measuring intradialytic changes in the blood volume. At first, it was an invasive dilution technique using ${ }^{131}$ I-labeled human albumin and/or ${ }^{51} \mathrm{Cr}$-labelled red blood cells. Since these methods were impractical and invasive, todays' devices, which are noninvasive and allowing continuous real-time monitoring of RBV, were invented $[92,93]$. These new devices either measure hematocrit $(\mathrm{Ht})$ levels by measuring hemoglobin levels using an optic spectroscopic technique $[94,95]$, which is also called Crit-Line method, or by measuring velocity of ultrasonographic waves traveling within the blood, which depends on the concentration of the total blood proteins $[92,96]$. Both methods give relative changes in the blood volume and usually represented as relative \% changes. As the fluid is removed, Ht or concentration of total blood proteins will rise mimicking the percent reductions in blood volume [97]. Today, RBV monitoring is a standard feature of most of modern dialysis devices [98]. 
There are quite a few studies, including very recent ones, showing the value of BVM in assessment of dry weight [94, 98-103]. A recent study by Kron et al. [98] investigated the use of RBV monitoring in renal replacement therapy patients with septic shock and they indicated RBV monitoring as an easy, safe, and feasible tool in fluid management. Another recent study by Balter et al. [101] used Crit-Lane method for 12 months to regulate fluid management and they found significant increases in average hemodialysis time, on-line clearance, and $\mathrm{Kt} / \mathrm{V}$; and decreases in post-dialysis systolic BP; and decreases in pre-dialysis SBP and anti-hypertensive medications in patients with hypertension at their first evaluation. However, they did not find any significant change in post-HD weight and intradialytic weight gain. As a major limitation to their study, they did not have any control group; instead they compared their data with preexisting clinical records that might be missing or inadequate for the data analysis [101]. Candan et al. [104] found similar results and stated that RBV monitoring was a useful tool to adjust dry weight providing a better BP control while causing no significant difference in intradialytic symptoms in pediatric HD patients. They found significant decreases by $0.5 \mathrm{~kg}$ in predialytic and $0.6 \mathrm{~kg}$ in postdialytic weights [104]. On the other hand, Steuer et al. [105] in their study found that 10 hemodialysis patients of the study group had tolerated additional fluid removal according to RBV monitoring results. They were able to increase ultrafiltration in 8 of these 10 patients and 6 of those 8 responded with decreased dry weight. Therefore, they concluded that with RBV monitoring, additional fluid removal can be achieved even in the absence of hypovolemic symptoms [105]. Similar conclusion has been stated by Merouani et al. [106] in pediatric patients. About morbidity and mortality, 2 studies found favorable results [107, 108]. In pediatric patients, Goldstein et al. [107] stated that by using Crit-Line method, hospitalization decreased significantly from 64 total days in 1999 to 4 total days in 2000 and 2001 combined without any significant increase in hypertensive episodes or antihypertensive medication administration. Gabrielli et al. [108], on the other hand, found that with RBV monitoring, intradialytic morbid events and treatment episodes for symptomatic hypotension decreased significantly in HD patients compared to standard HD. However, the study had several weaknesses due to its short duration (6 weeks), lack of wash-out period (in their study, each patient served as their own control and they used standard HD for 6 weeks then RBV monitoring in the fol- lowing 6 weeks), and potential bias risk since funded by an industrial corporation [108].

Intradialytic hypotension (IDH) is an important subject during dialysis for which some studies indicated the benefit of RBV monitoring $[109,110]$. IDH is associated with an increase in overall morbidity and mortality [111113]. Therefore, keeping dry weight as low as possible without causing IDH should be the primary aim. However, it is not as easy as it sounds, since RBV is not just affected by ultrafiltration but by many other factors, vascular refilling being the foremost. Vascular refilling, on the other hand, is affected by 2 main factors including ultrafiltration rate and patient specific parameters, which include volume overload, transcapillary hydrostatic and oncotic pressure gradients, and capillary wall characteristics [114]. However, there is a recent study suggesting that vascular refilling is independent of fluid overload in HD patients with moderate volume excess [115]. When the rate of vascular refilling is less than the rate of ultrafiltration, RBV will decline and this might lead to IDH. Therefore, balancing vascular refilling and rate of ultrafiltration may enable us to remove more fluid without causing IDH.

There are also studies indicating the limitations and unfavorable outcomes of RBV monitoring [93, 97, 109, 116-118]. First of all, as mentioned before, RBV is not just affected by ultrafiltration but by many other factors and it is difficult to achieve the balance between vascular refilling and rate of ultrafiltration [114]. With vascular refilling, not only intravascular compartment, which RBV estimates, but also extracellular compartment is included in the equation. Therefore, to maximize the fluid removal without causing IDH, continuous RBV monitoring (predialysis, during dialysis, and postdialysis) and adjusting the ultrafiltration rate accordingly might be helpful. This adjustment is particularly very important in patients with significant comorbidities such as heart disease and diabetes mellitus for whom chronic hypervolemia might further compromise their health status, while the same risk is present with IDH, as well. Therefore, to achieve ideal dry weight without developing IDH, lower ultrafiltration rates and/or longer dialysis sessions may be performed [97]. Rodriguez et al. [97] also suggested that RBV monitoring solely might not be enough, but using clinical assessment of hypovolemia with RBV monitoring might give better outcomes.

Krepel et al. [118] did not find any correlation between RBV monitoring and incidence of IDH or BP in 10 studied patients. They concluded that RBV monitoring was limited in prevention of IDH due to high intra-
Ekinci/Karabork/Siriopol/Dincer/Covic/ Kanbay 
and inter-individual variability [118]. Dasselaar et al. [93] review also reached a similar conclusion and stated that since there are many factors (posture of patient, blood transfusions, splanchnic vasoconstriction, individualized ability of plasma refilling) influencing $\mathrm{Ht}$ concentration, variation in RBV changes even for the same individual was not a surprise. Therefore, it was not even possible to set a standard for an individual. As another limitation, they stated that although RBV monitoring relies on a uniform mixing of $\mathrm{Ht}$ or total plasma proteins throughout the whole circulation, this is not the case in reality; even worse, this non-uniform distribution may change with exercise, heat stress, and standing for a long time. They also suggested that the decrease in the frequency of IDH was not due to a significantly different plasma volume reduction between RBV monitoring and classical HD but possibly due to a favorable effect of RBV monitoring by avoiding rapid fluctuations in RBV [93]. In a large observational study including 123 patients, Andrulli et al. [119] also reached a similar conclusion that intradialytic changes in RBV cannot predict whether a patient will be hypotensive, normotensive, or hypertensive. They did not find a significant relationship between $\mathrm{BP}$ and $\mathrm{RBV}$, thereby suggesting that RBV monitoring had a relatively low power in the detection and prediction of IDH. They stated that major causes of differences in BP were related to differences in individual cardiovascular regulatory systems instead of the differences in RBV reductions [119]. Maduell et al. [117], on the other hand, reported favorable outcomes with RBV monitoring in the high fluid excess, whereas sensitivity of RBV monitoring for moderate or low fluid excesses was questionable. They described the sensitivity of RBV monitoring curve as the shape of a bathtub, having the least sensitivity in the middle (moderate volume excess) followed by low volume excess and best at high volume excess [117]. Another study reporting unfavorable outcomes with RBV monitoring was one of the largest randomized studies done in HD patients and took place in 6 centers including 443 patients over a 6-month period. In their study, Reddan et al. [116] compared the Crit-Lane method (227 patients) with conventional clinical monitoring (216 patients). They reported no significant differences in estimated dry weight or pre- and post-dialytic systolic and diastolic BPs, whereas they found significantly higher hospitalization (both non-access and access-related) and mortality rates in Crit-Lane methods compared to conventional monitoring. Although as they indicated the results might have been different with a longer observation period, due to its high power with a relatively large

Volume Evaluation in CKD sample size, this study is one of the foremost studies that brings out the validity of RBV monitoring to question [116].

To conclude, while there are ongoing discussions questioning the validity of RBV monitoring, with the recent favorable outcomes [98-101], it is still one of the most commonly used methods in HD settings to assess volume status today. However, there is definitely need for randomized controlled studies with large sample sizes to solve the conflict about the validity of RBV monitoring. The conflicts about the reliability and the results of RBV monitoring could be solved by new techniques that allow the estimation of absolute blood volumes [120-122]. Although there are a lot of unsolved disputes about RBV monitoring, it is definite that this area is an active area of research promoting scientists to take part in.

\section{Bioimpedance}

The use of electrical bioimpedance to assess hydration status is an up-and-coming method that has been increasingly used due to its alluring features as being simple, inexpensive, and noninvasive [123-125]. Bioelectrical impedance analysis (BIA) actually came to light in the mid1980s with commercial availability of impedance analyzers $[126,127]$. At first, BIA use took a great extent in nutritional assessment [124], but in time its use also expanded into the area of health monitoring among the general population $[126,128]$. Although there are varying types and methods of measurement, today the fundamental principles of BIA remain the same.

Body fluid volumes' calculation via BIA is based on the hypothesis that the penetration of the electrical current has variations in extracellular (ECW) and intracellular water spaces due to the variance in resistive indices of these 2 spaces. High-frequency current can flow through both spaces, while low-frequency current can only flow through the ECW space $[125,129]$. BIA can be used in various forms as single- or multiple-frequency and segmental or whole body analysis. Only one alternating current frequency is provided in a single-frequency technique, whereas a range of frequencies are supplied in the multiple-frequency method [130]. On the other hand, the difference between whole body and segmental bioimpedance is that only a part of the body (particularly the calf) is used for the segmental bioimpedance, whereas the current is administered to the entire body in the whole body bioimpedance technique [131-133]. In the segmental bioimpedance, it predicts the whole body volumes by sum- 
ming up the respective segments' (arms, legs, and trunk) impedance measurements; but in this method, resistivity of the individual segments (arms, legs, and trunks) are considered equal. However, in reality, the composition of body parts are not distributed equally [126].

The single-frequency BIA has shown beneficial effects by guiding HD patients toward normohydration and providing a better BP control $[123,129]$. Furthermore, the single-frequency approach is simpler and cheaper compared to the multiple-frequency BIA [134]. However, the single-frequency approach cannot report the ideal dry weight, only the relative changes in fluid status can be detected. [135]. The multiple-frequency approach seems to be more accurate, since there is an attempt to incorporate underlying physical principles into equations [129]. Whole body BIA spectroscopy has now been widely used in the clinical settings for the management of ESRD patients [136-138]. Chamney et al. [138] successfully achieved post-dialysis weight of 30 healthy subjects to reach normovolemia. Furthermore, they were successful to achieve $86 \%$ decrease in the use of antihypertensive medications [138]. More importantly, there are also studies indicating that BIA has been shown to predict mortality in ESRD patients $[137,139,140]$.

BIA is thought to be an objective fluid status assessment method, which is shown superior to classical methods such as BP monitoring and weight control in many studies $[123,124,129,141,142]$. There is evidence supporting the fact that whole-body BIA is in excellent agreement with all gold standard comparisons for both healthy and HD patient groups $[129,143]$. In their randomized controlled study, Onofriescu et al. [123] compared BIA to these classical methods for fluid assessment, and showed a better fluid volume control in HD patients in aspects as relative fluid overload, SBP measurements, need for antihypertensive therapy, and mortality. Wabel et al. [141] found similar findings, concluding that whole-body BIA spectroscopy can be used to achieve appropriate fluid balance with a consecutive reduction in mortality. In their study, they concluded that whole-body bioimpedance is an objective method for obtaining clinical fluid balance especially when combined with physiological tissue model $[123,141]$. In another study, Marcelli et al. [144] used multi-frequency BIA spectroscopy to evaluate body compositions and its effect on the outcome compared to only taking BMI into account in ESRD patients. They reported that there is a strong relationship between the BIA assessment results and patients' outcome, supporting the functional validity of the method [144].
Siriopol et al. [74] showed that LUS had lower sensitivity despite better specificity compared to BIA for allcause mortality and suggested BIA as a better screening tool, whereas the LUS could be used as the next step for further investigations. On the other hand, in an older study, the same group had found that risk prediction for death by assessing fluid status was improved only by using BIA but not by using LUS [76]. Although the majority of the previous observational studies showed a reduction in mortality in ESRD patients, in a recent metaanalysis that included only randomized controlled trials, BIA was not associated with a significant improvement in survival, showing only a better BP control [25].

Arroyo et al. [145] showed a limitation of BIS in patients with intra-abdominal fluid. By using BIS, they compared the fluid status in patients with either full or empty peritoneal cavity and found that fluid overload was overestimated in patients with dialysate in the peritoneal cavity. This overestimation was greater in younger, nourished poorer, or less overhydrated patients. Therefore, they suggested that for more accurate measurements, the peritoneal cavity should be drained before performing BIS [145]. In another study, Davies et al. [146] suggested that BIA cannot differentiate plasma volume from the volume in the extravascular compartment, such as edema. This causes progressive tissue overhydration in patients with muscle-wasting, which is a common abnormality seen in HD patients. They also add that if continuous weight loss is sustained according to the ECW assessment by BIA, this may further compromise the already damaged kidney functions, since the expansion of ECW may not be equal to plasma volume expansion. At last, they suggested that combining BIA with biomarkers like BNP may be helpful to reach the target dry weight [146].

\section{Limitations}

This technique has several limitations. Its accuracy is limited in children, pregnant women, or subjects wearing a pacemaker. The BIA assessment could also be affected by extreme obesity or eating, intense physical activity, and fluid intake before the evaluation. Importantly, BIA does not accurately estimate fluid change during HD [147]. It was also suggested that BIA cannot differentiate plasma volume from the volume in the extravascular compartment and that combining BIA with biomarkers like BNP may be helpful to reach the target dry weight [146], thereby improving patients' outcomes [148].
Ekinci/Karabork/Siriopol/Dincer/Covic/ Kanbay 


\section{Less Commonly Used Objective Methods}

Measuring left atrial volume is a method used to evaluate volume status. There are also some other parameters that are used in echocardiography to evaluate fluid status such as left ventricular thickness, left ventricular mass and diameters, the ejection fraction, and parameters of diastolic dysfunction $[149,150]$. However, Ozdogan et al. [150] suggested that left atrial volume index was the only independent factor determining the mortality in low-risk dialysis patients. Although echocardiography might be considered a reliable method, its application might have some challenges. In severely ill patients, performing an echocardiography might be challenging due to difficulties in repositioning the patient and also because there is a requirement of a set of skills [84]. Therefore, it might be unfeasible to perform an echocardiography by any physician in intensive care units or emergency departments.

PAC is another less commonly used method to evaluate volume status. Although it was successfully used before to evaluate volume status especially in critically ill patients $[79,80,151]$, it is now almost completely abandoned mainly due to its invasive nature. There are also meta-analyses questioning the accuracy of this technique to determine volume responsiveness $[152,153]$. Therefore, other objective methods should be preferred over PAC for the evaluation of volume status.

Another rarely used method is measuring aortic blood flow by using ED monitoring. By using respiratory variations in aortic blood flow, fluid status can be evaluated especially in mechanically ventilated patients [154]. Although this method is less invasive compared to PAC, it is still invasive in comparison to other objective methods like CA ultrasonography or bioimpedance analyses techniques.

Suprasternal Doppler monitorizing ascending or descending aorta has been used since the 1960s $[155,156]$. Although monitoring cardiac output via suprasternal Doppler was feasible, Elwan et al. [155] showed that cardiac output was underestimated as shown before by Chong et al. [157]. Elwan et al. [155] also compared suprasternal Doppler technique to the bioimpedance method. Although the bioimpedance method gave better results, they emphasized that lower readings in suprasternal Doppler might have resulted from operator dependence [155]. Therefore, there is a need for further studies to establish reference standards for Suprasternal Doppler monitorization.

Blood viscosity can be calculated using the Hagen-Poiseuille formula and is a determinant of blood flow rate [158]. There are studies suggesting that blood viscosity correlates with intravascular volume changes. In these studies, the blood viscosity method is mainly compared to BVM technique measuring the Ht levels [158-160]. Although both methods successfully achieved to manage fluid status, blood viscosity monitoring had some drawbacks. Blood viscosity monitoring was more inconvenient and the results were affected by the shear-rate [158]. Although a later study showed that changes in Ht levels correlated with the changes in shear-rate [159], there is a need for further studies to consolidate the efficacy of blood viscosity monitoring.

\section{Conclusion}

Volume overload and congestion are very serious problems causing morbidity and mortality in HD patients [1-6]. Therefore, it is quite important to avoid volume overload and maintain dry weight in HD patients. Although clinical evaluation methods are still the most commonly used ones [22], recent studies show that objective methods are being preferred more day by day. Particularly, bioimpedance, RBV monitoring, and lung ultrasonography techniques look more promising in the future compared to the other objective methods in light of recent publications. Among these, the multi-frequency BIS technique is especially shining out, since it can provide far more information including ECW and TBW. However, there is still a need for further randomized control studies, especially the ones comparing these objective methods although they are increasing in number recently.

\section{Disclosure Statement}

There is no conflict of interest by the authors.

\section{References}

1 Arikan AA, Zappitelli M, Goldstein SL, Naipaul A, Jefferson LS, Loftis LL: Fluid overload is associated with impaired oxygenation and morbidity in critically ill children. Pediatr Crit Care Med 2012;13:253-258.

2 Hassinger AB, Wald EL, Goodman DM: Early postoperative fluid overload precedes acute kidney injury and is associated with higher morbidity in pediatric cardiac surgery patients. Pediatr Crit Care Med 2014;15:131-138.

3 Magee G, Zbrozek A: Fluid overload is associated with increases in length of stay and hospital costs: pooled analysis of data from more than 600 US hospitals. Clinicoecon Outcomes Res 2013;5:289-296. 
4 Vaara ST, Korhonen AM, Kaukonen KM, Nisula S, Inkinen O, Hoppu S, et al: Fluid overload is associated with an increased risk for 90-day mortality in critically ill patients with renal replacement therapy: data from the prospective FINNAKI study. Crit Care 2012; 16:R197.

5 Mees EJ: Volaemia and blood pressure in renal failure: have old truths been forgotten? Nephrol Dial Transplant 1995;10:1297-1298.

6 Zoccali C, Torino C, Tripepi R, Tripepi G, D’Arrigo G, Postorino M, et al: Pulmonary congestion predicts cardiac events and mortality in ESRD. J Am Soc Nephrol 2013;24: 639-646.

7 Collins AJ, Foley RN, Gilbertson DT, Chen SC: United States Renal Data System public health surveillance of chronic kidney disease and end-stage renal disease. Kidney Int Suppl (2011) 2015;5:2-7.

8 Chatterjee S, Bavishi C, Sardar P, Agarwal V, Krishnamoorthy P, Grodzicki T, et al: Metaanalysis of left ventricular hypertrophy and sustained arrhythmias. Am J Cardiol 2014; 114:1049-1052.

9 Aidietis A, Laucevicius A, Marinskis G: Hypertension and cardiac arrhythmias. Curr Pharm Des 2007;13:2545-2555.

10 Salem M: Hypertension in the hemodialysis population? High time for answers. Am J Kidney Dis 1999;33:592-594.

11 Foley RN, Parfrey PS, Harnett JD, Kent GM, Murray DC, Barre PE: Impact of hypertension on cardiomyopathy, morbidity and mortality in end-stage renal disease. Kidney Int 1996;49:1379-1385.

12 Arneson TJ, Liu J, Qiu Y, Gilbertson DT, Foley RN, Collins AJ: Hospital treatment for fluid overload in the Medicare hemodialysis population. Clin J Am Soc Nephrol 2010;5: 1054-1063.

13 Saad E, Charra B, Raj DS: Hypertension control with daily dialysis. Semin Dial 2004;17: 295-298.

14 Jaeger JQ, Mehta RL: Assessment of dry weight in hemodialysis: an overview. J Am Soc Nephrol 1999;10:392-403.

15 Weitzel WF, Hamilton J, Wang X, Bull JL, Vollmer A, Bowman A, et al: Quantitative lung ultrasound comet measurement: method and initial clinical results. Blood Purif 2015;39:37-44.

16 Onofriescu M, Siriopol D, Voroneanu L, Hogas S, Nistor I, Apetrii M, et al: Overhydration, cardiac function and survival in hemodialysis patients. PLoS One 2015;10: e0135691.

17 Hur E, Usta M, Toz H, Asci G, Wabel P, Kahvecioglu $S$, et al: Effect of fluid management guided by bioimpedance spectroscopy on cardiovascular parameters in hemodialysis patients: a randomized controlled trial. Am J Kidney Dis 2013;61:957-965.

18 Ok E, Asci G, Chazot C, Ozkahya M, Mees EJ: Controversies and problems of volume control and hypertension in haemodialysis. Lancet 2016;388:285-293.
19 Mimoz O, Rauss A, Rekik N, Brun-Buisson C, Lemaire F, Brochard L: Pulmonary artery catheterization in critically ill patients: a prospective analysis of outcome changes associated with catheter-prompted changes in therapy. Crit Care Med 1994;22:573-579.

20 Thomson GE, Waterhouse K, McDonald HP Jr, Friedman EA: Hemodialysis for chronic renal failure. Clinical observations. Arch Intern Med 1967;120:153-167.

21 Henderson LW: Symptomatic hypotension during hemodialysis. Kidney Int 1980;17: 571-576.

22 Sinha AD: Why assistive technology is needed for probing of dry weight. Blood Purif 2011; 31:197-202.

23 Wo CC, Shoemaker WC, Appel PL, Bishop $\mathrm{MH}$, Kram HB, Hardin E: Unreliability of blood pressure and heart rate to evaluate cardiac output in emergency resuscitation and critical illness. Crit Care Med 1993;21:218223.

24 Marik PE, Monnet X, Teboul JL: Hemodynamic parameters to guide fluid therapy. Ann Intensive Care 2011;1:1

25 Covic A, Ciumanghel AI, Siriopol D, Kanbay M, Dumea R, Gavrilovici C, et al: Value of bioimpedance analysis estimated "dry weight" in maintenance dialysis patients: a systematic review and meta-analysis. Int Urol Nephrol 2017;49:2231-2245.

26 Sun L, Sun Y, Zhao X, Xu C, Chen D, Li L, et al: Predictive role of BNP and NT-proBNP in hemodialysis patients. Nephron Clin Pract 2008;110:c178-c184.

27 Hossein-Nejad H, Mohammadinejad P, Lessan-Pezeshki M, Davarani SS, Banaie M: Carotid artery corrected flow time measurement via bedside ultrasonography in monitoring volume status. J Crit Care 2015;30:11991203.

28 Mukoyama M, Nakao K, Hosoda K, Suga S, Saito Y, Ogawa Y, et al: Brain natriuretic peptide as a novel cardiac hormone in humans. Evidence for an exquisite dual natriuretic peptide system, atrial natriuretic peptide and brain natriuretic peptide. J Clin Invest 1991; 87:1402-1412.

29 Kinnunen P, Vuolteenaho O, Ruskoaho H: Mechanisms of atrial and brain natriuretic peptide release from rat ventricular myocardium: effect of stretching. Endocrinology 1993;132:1961-1970.

30 Rascher W, Tulassay T, Lang RE: Atrial natriuretic peptide in plasma of volume-overloaded children with chronic renal failure. Lancet 1985;2:303-305.

31 Mueller C, Laule-Kilian K, Scholer A, Nusbaumer C, Zeller T, Staub D, et al: B-type natriuretic peptide for acute dyspnea in patients with kidney disease: insights from a randomized comparison. Kidney Int 2005;67:278284.

32 McCullough PA, Duc P, Omland T, McCord J, Nowak RM, Hollander JE, et al: B-type natriuretic peptide and renal function in the diagnosis of heart failure: an analysis from the
Breathing Not Properly Multinational Study. Am J Kidney Dis 2003;41:571-579.

33 Cataliotti A, Malatino LS, Jougasaki M, Zoccali C, Castellino P, Giacone G, et al: Circulating natriuretic peptide concentrations in patients with end-stage renal disease: role of brain natriuretic peptide as a biomarker for ventricular remodeling. Mayo Clin Proc 2001; 76:1111-1119.

34 Agarwal R: B-type natriuretic peptide is not a volume marker among patients on hemodialysis. Nephrol Dial Transplant 2013;28: 3082-3089.

35 Fagugli RM, Vecchi L, Valente F, Santirosi P, Laviola MM: Comparison between oscillometric and auscultatory methods of ambulatory blood pressure measurement in hemodialysis patients. Clin Nephrol 2002;57:283288.

36 Sivalingam M, Vilar E, Mathavakkannan S, Farrington $\mathrm{K}$ : The role of natriuretic peptides in volume assessment and mortality prediction in Haemodialysis patients. BMC Nephrol 2015; 16:218.

37 Voroneanu L, Siriopol D, Apetrii M, Hogas S, Onofriescu M, Nistor I, et al: Prospective validation of a screening biomarker approach combining amino-terminal pro-brain natriuretic peptide with galectin-3 predicts death and cardiovascular events in asymptomatic hemodialysis patients. Angiology 2017, Epub ahead of print.

38 Lang CC, Choy AM, Henderson IS, Coutie WJ, Struthers AD: Effect of haemodialysis on plasma levels of brain natriuretic peptide in patients with chronic renal failure. Clin Sci (Lond) 1992;82:127-131.

39 Taub PR, Fields JD, Wu AH, Miss JC, Lawton MT, Smith WS, et al: Elevated BNP is associated with vasospasm-independent cerebral infarction following aneurysmal subarachnoid hemorrhage. Neurocrit Care 2011;15: 13-18.

40 Kimura K, Shibazaki K, Iguchi Y, Aoki J, Sakai $\mathrm{K}$, Sakamoto Y, et al: The combination of elevated BNP and AF as a predictor of no early recanalization after IV-t-PA in acute ischemic stroke. J Neurol Sci 2010;290:37-40.

41 Li N, Zhang Y, Fan S, Xing J, Liu H: BNP and NT-proBNP levels in patients with sepsis. Front Biosci (Landmark Ed) 2013;18:12371243.

42 Barberis VI, Komnou AE, Pistevos AC: Markedly elevated BNP levels unrelated to heart failure in a young septic patient postcesarean section. Eur J Intern Med 2007;18: 608-609.

43 Mansoor A, Althoff K, Gange S, Anastos K, Dehovitz J, Minkoff H, et al: Elevated NTpro-BNP levels are associated with comorbidities among HIV-infected women. AIDS Res Hum Retroviruses 2009;25:997-1004.

44 Mirsaeidi M, Omar HR, Baughman R, Machado R, Sweiss N: The association between BNP, 6MWD test, DLCO\% and pulmonary hypertension in sarcoidosis. Sarcoidosis Vasc Diffuse Lung Dis 2016;33:317-320. 
45 Konig K, Guy KJ, Walsh G, Drew SM, Barfield CP: Association of BNP, NTproBNP, and early postnatal pulmonary hypertension in very preterm infants. Pediatr Pulmonol 2016;51: 820-824.

46 Gutte H, Mortensen J, Jensen CV, von der Recke P, Petersen CL, Kristoffersen US, et al: $\mathrm{ANP}, \mathrm{BNP}$ and $\mathrm{D}$-dimer predict right ventricular dysfunction in patients with acute pulmonary embolism. Clin Physiol Funct Imaging 2010;30:466-472.

47 Pasha SM, Klok FA, van der Bijl N, de Roos A, Kroft LJ, Huisman MV: NT-pro-BNP levels in patients with acute pulmonary embolism are correlated to right but not left ventricular volume and function. Thromb Haemost 2012;108:367-372.

48 Palazzuoli A, Quatrini I, Calabro A, Antonelli G, Caputo M, Campagna MS, et al: Anemia correction by erythropoietin reduces BNP levels, hospitalization rate, and NYHA class in patients with cardio-renal anemia syndrome. Clin Exp Med 2011;11:43-48.

$49 \mathrm{Wu}$ AH, Omland T, Wold Knudsen C, McCord J, Nowak RM, Hollander JE, et al: Relationship of B-type natriuretic peptide and anemia in patients with and without heart failure: a substudy from the Breathing Not Properly (BNP) Multinational Study. Am J Hematol 2005;80:174-180.

50 Licata A, Corrao S, Petta S, Genco C, Cardillo $\mathrm{M}$, Calvaruso V, et al: NT pro BNP plasma level and atrial volume are linked to the severity of liver cirrhosis. PLoS One 2013; 8:e68364.

51 Vaida LS, Lozyns'ka NV: [The relation of structural and functional status of the left chambers of the heart, the level of circulating NT-pro-BNP and the status of endothelium dependent vasodilation with characteristics of 24 hour blood pressure monitoring in patients with arterial hypertension]. Lik Sprava 2013;3:16-24

52 Natori H, Tamaki S, Kira S: Ultrasonographic evaluation of ventilatory effect on inferior vena caval configuration. Am Rev Respir Dis 1979; 120:421-427.

53 Jeffrey RB Jr, Federle MP: The collapsed inferior vena cava: CT evidence of hypovolemia. AJR Am J Roentgenol 1988;150:431-432.

54 Nakao S, Come PC, McKay RG, Ransil BJ: Effects of positional changes on inferior vena caval size and dynamics and correlations with right-sided cardiac pressure. Am J Cardiol 1987;59:125-132.

55 Takata M, Wise RA, Robotham JL: Effects of abdominal pressure on venous return: abdominal vascular zone conditions. J Appl Physiol (1985) 1990;69:1961-1972.

56 Kircher BJ, Himelman RB, Schiller NB: Noninvasive estimation of right atrial pressure from the inspiratory collapse of the inferior vena cava. Am J Cardiol 1990;66:493496.

57 Barbier C, Loubieres Y, Schmit C, Hayon J, Ricome JL, Jardin F, et al: Respiratory changes in inferior vena cava diameter are helpful in predicting fluid responsiveness in ventilated septic patients. Intensive Care Med 2004; 30:1740-1746.

58 Levine AC, Shah SP, Umulisa I, Munyaneza RB, Dushimiyimana JM, Stegmann K, et al: Ultrasound assessment of severe dehydration in children with diarrhea and vomiting. Acad Emerg Med 2010;17:1035-1041.

59 Feissel M, Michard F, Faller JP, Teboul JL: The respiratory variation in inferior vena cava diameter as a guide to fluid therapy. Intensive Care Med 2004;30:1834-1837.

60 Lyon M, Blaivas M, Brannam L: Sonographic measurement of the inferior vena cava as a marker of blood loss. Am J Emerg Med 2005; 23:45-50.

61 Baker EC, Pott J, Khan F, Freund Y, Harris $\mathrm{T}$ : Best approach to measuring the inferior vena cava in spontaneously ventilating patients: a pilot study. Eur J Emerg Med 2015; 22:58-61.

62 Nagdev AD, Merchant RC, Tirado-Gonzalez A, Sisson CA, Murphy MC: Emergency department bedside ultrasonographic measurement of the caval index for noninvasive determination of low central venous pressure. Ann Emerg Med 2010;55:290-295.

63 Blehar DJ, Resop D, Chin B, Dayno M, Gaspari R: Inferior vena cava displacement during respirophasic ultrasound imaging. Crit Ultrasound J 2012;4:18.

64 Wallace DJ, Allison M, Stone MB: Inferior vena cava percentage collapse during respiration is affected by the sampling location: an ultrasound study in healthy volunteers. Acad Emerg Med 2010;17:96-99.

65 Muller L, Bobbia X, Toumi M, Louart G, Molinari N, Ragonnet B, et al: Respiratory variations of inferior vena cava diameter to predict fluid responsiveness in spontaneously breathing patients with acute circulatory failure: need for a cautious use. Crit Care 2012;16: R188.

66 Juhl-Olsen P, Vistisen ST, Christiansen LK, Rasmussen LA, Frederiksen CA, Sloth E: Ultrasound of the inferior vena cava does not predict hemodynamic response to early hemorrhage. J Emerg Med 2013;45:592-597.

67 Picano E, Gargani L, Gheorghiade M: Why, when, and how to assess pulmonary congestion in heart failure: pathophysiological, clinical, and methodological implications. Heart Fail Rev 2010;15:63-72.

68 Lichtenstein DA, Meziere GA: Relevance of lung ultrasound in the diagnosis of acute respiratory failure: the BLUE protocol. Chest 2008; 134:117-125.

69 Picano E, Frassi F, Agricola E, Gligorova S, Gargani L, Mottola G: Ultrasound lung comets: a clinically useful sign of extravascular lung water. J Am Soc Echocardiogr 2006;19: 356-363.

70 Volpicelli G, Elbarbary M, Blaivas M, Lichtenstein DA, Mathis G, Kirkpatrick AW, et al: International evidence-based recommendations for point-of-care lung ultrasound. Intensive Care Med 2012;38:577-591.
71 Panuccio V, Enia G, Tripepi R, Torino C, Garozzo $M$, Battaglia GG, et al: Chest ultrasound and hidden lung congestion in peritoneal dialysis patients. Nephrol Dial Transplant 2012; 27:3601-3605.

72 Donadio C, Bozzoli L, Colombini E, Pisanu G, Ricchiuti G, Picano E, et al: Effective and timely evaluation of pulmonary congestion: qualitative comparison between lung ultrasound and thoracic bioelectrical impedance in maintenance hemodialysis patients. Medicine (Baltimore) 2015;94:e473.

73 Noble VE, Murray AF, Capp R, Sylvia-Reardon $\mathrm{MH}$, Steele DJR, Liteplo A: Ultrasound assessment for extravascular lung water in patients undergoing hemodialysis. Time course for resolution. Chest 2009;135:14331439.

74 Siriopol D, Onofriescu M, Voroneanu L, Apetrii M, Nistor I, Hogas S, et al: Dry weight assessment by combined ultrasound and bioimpedance monitoring in low cardiovascular risk hemodialysis patients: a randomized controlled trial. Int Urol Nephrol 2017;49:143153.

75 Siriopol D, Hogas S, Voroneanu L, Onofriescu M, Apetrii M, Oleniuc M, et al: Predicting mortality in haemodialysis patients: a comparison between lung ultrasonography, bioimpedance data and echocardiography parameters. Nephrol Dial Transplant 2013;28: 2851-2859.

76 Siriopol D, Voroneanu L, Hogas S, Apetrii M, Gramaticu A, Dumea R, et al: Bioimpedance analysis versus lung ultrasonography for optimal risk prediction in hemodialysis patients. Int J Cardiovasc Imaging 2016;32:263270.

77 Soldati G, Copetti R, Sher S: Can lung comets be counted as "objects"? JACC Cardiovasc Imaging 2011;4:438-439.

78 Picano E, Pellikka PA: Ultrasound of extravascular lung water: a new standard for pulmonary congestion. Eur Heart J 2016;37: 2097-2104.

79 Wilson JN, Grow JB, Demong CV, Prevedel AE, Owens JC: Central venous pressure in optimal blood volume maintenance. Arch Surg 1962;85:563-578.

80 Hughes RE, Magovern GJ: The relationship between right atrial pressure and blood volume. AMA Arch Surg 1959;79:238-243.

81 Roeck M, Jakob SM, Boehlen T, Brander L, Knuesel R, Takala J: Change in stroke volume in response to fluid challenge: assessment using esophageal Doppler. Intensive Care Med 2003;29:1729-1735.

82 Chen G, Meng L, Alexander B, Tran NP, Kain ZN, Cannesson M: Comparison of noninvasive cardiac output measurements using the Nexfin monitoring device and the esophageal Doppler. J Clin Anesth 2012;24: 275-283.

83 Prentice D, Sona C: Esophageal Doppler monitoring for hemodynamic assessment. Crit Care Nurs Clin North Am 2006;18:189193, x. 
84 Blehar DJ, Glazier S, Gaspari RJ: Correlation of corrected flow time in the carotid artery with changes in intravascular volume status. J Crit Care 2014;29:486-488.

85 Mackenzie DC, Khan NA, Blehar D, Glazier S, Chang Y, Stowell CP, et al: Carotid flow time changes with volume status in acute blood loss. Ann Emerg Med 2015;66:277-282.e1.

86 Hilbert T, Klaschik S, Ellerkmann RK, Putensen C, Thudium M: Common carotid artery diameter responds to intravenous volume expansion: an ultrasound observation. Springerplus 2016;5:853.

87 Shokoohi H, Berry GW, Shahkolahi M, King J, King J, Salimian M, et al: The diagnostic utility of sonographic carotid flow time in determining volume responsiveness. J Crit Care 2016;38:231-235.

88 Stolz LA, Mosier JM, Gross AM, Douglas MJ, Blaivas M, Adhikari S: Can emergency physicians perform common carotid doppler flow measurements to assess volume responsiveness? West J Emerg Med 2015;16:255-259.

89 Marik PE, Levitov A, Young A, Andrews L: The use of bioreactance and carotid Doppler to determine volume responsiveness and blood flow redistribution following passive leg raising in hemodynamically unstable patients. Chest 2013;143:364-370.

90 Peachey T, Tang A, Baker EC, Pott J, Freund $\mathrm{Y}$, Harris T: The assessment of circulating volume using inferior vena cava collapse index and carotid Doppler velocity time integral in healthy volunteers: a pilot study. Scand J Trauma Resusc Emerg Med 2016;24:108.

91 Keith NM, Rowntree LG, Geraghty JT: A method for the determination of plasma and blood volume. Arch Intern Med 1915; XVI:547-576.

92 Schneditz D, Pogglitsch H, Horina J, Binswanger U: A blood protein monitor for the continuous measurement of blood volume changes during hemodialysis. Kidney Int 1990;38:342-346

93 Dasselaar JJ, Huisman RM, de Jong PE, Franssen CF: Measurement of relative blood volume changes during haemodialysis: merits and limitations. Nephrol Dial Transplant 2005;20:2043-2049.

94 Steuer RR, Harris DH, Conis JM: A new optical technique for monitoring hematocrit and circulating blood volume: Its application in renal dialysis. Dial Transplant 1993;22:260-265.

95 Mancini E, Santoro A, Spongano M, Paolini F, Rossi M, Zucchelli P: Continuous on-line optical absorbance recording of blood volume changes during hemodialysis. Artif Organs 1993; 17:691-694.

96 Johner C, Chamney PW, Schneditz D, Kramer M: Evaluation of an ultrasonic blood volume monitor. Nephrol Dial Transplant 1998; 13:2098-2103.

97 Rodriguez HJ, Domenici R, Diroll A, Goykhman I: Assessment of dry weight by monitoring changes in blood volume during hemodialysis using Crit-Line. Kidney Int 2005;68:854-861.
98 Kron S, Leimbach T, Wenkel R, Thieme U, Kern H, Kron J: Relative blood volume monitoring during renal replacement therapy in critically Ill patients with septic shock: a preliminary report. Blood Purif 2015;40:133138.

99 Srisuwan K, Hongsawong N, Lumpaopong A, Thirakhupt P, Chulamokha Y: Blood volume monitoring to assess dry weight in pediatric chronic hemodialysis patients. J Med Assoc Thai 2015;98:1089-1096.

100 Hussein WF, Arramreddy R, Sun SJ, DossMcQuitty S, Schiller B: Blood volume monitoring to assist fluid management in hemodialysis patients. Am J Kidney Dis 2016;67: 166-168.

101 Balter P, Ficociello LH, Taylor PB, Usvyat L, Sawin DA, Mullon C, et al: A year-long quality improvement project on fluid management using blood volume monitoring during hemodialysis. Curr Med Res Opin 2015; 31:1323-1331.

102 Barth C, Boer W, Garzoni D, Kuenzi T, Ries W, Schaefer R, et al: Characteristics of hypotension-prone haemodialysis patients: is there a critical relative blood volume? Nephrol Dial Transplant 2003;18:13531360.

103 Lopot F, Kotyk P, Blaha J, Forejt J: Use of continuous blood volume monitoring to detect inadequately high dry weight. Int J Artif Organs 1996;19:411-414.

104 Candan C, Sever L, Civilibal M, Caliskan S, Arisoy N: Blood volume monitoring to adjust dry weight in hypertensive pediatric hemodialysis patients. Pediatr Nephrol 2009; 24:581-587.

105 Steuer RR, Germain MJ, Leypoldt JK, Cheung AK: Enhanced fluid removal guided by blood volume monitoring during chronic hemodialysis. Artif Organs 1998;22:627632.

106 Merouani A, Kechaou W, Litalien C, Ducruet T, Jouvet P: Impact of blood volume monitoring on fluid removal during intermittent hemodialysis of critically ill children with acute kidney injury. Nephrol Dial Transplant 2011;26:3315-3319.

107 Goldstein SL, Smith CM, Currier H: Noninvasive interventions to decrease hospitalization and associated costs for pediatric patients receiving hemodialysis. J Am Soc Nephrol 2003;14:2127-2131.

108 Gabrielli D, Krystal B, Katzarski K, Youssef M, Hachache T, Lopot F, et al: Improved intradialytic stability during haemodialysis with blood volume-controlled ultrafiltration. J Nephrol 2009;22:232-240.

109 Nesrallah GE, Suri RS, Guyatt G, Mustafa RA, Walter SD, Lindsay RM, et al: Biofeedback dialysis for hypotension and hypervolemia: a systematic review and meta-analysis. Nephrol Dial Transplant 2013;28:182-191.

110 Jain SR, Smith L, Brewer ED, Goldstein SL: Non-invasive intravascular monitoring in the pediatric hemodialysis population. Pediatr Nephrol 2001;16:15-18.
111 Shoji T, Tsubakihara Y, Fujii M, Imai E: Hemodialysis-associated hypotension as an independent risk factor for two-year mortality in hemodialysis patients. Kidney Int 2004; 66:1212-1220.

112 Zager PG, Nikolic J, Brown RH, Campbell MA, Hunt WC, Peterson D, et al: "U" curve association of blood pressure and mortality in hemodialysis patients. Medical Directors of Dialysis Clinic, Inc. Kidney Int 1998;54: 561-569.

113 Burton JO, Jefferies HJ, Selby NM, McIntyre $\mathrm{CW}$ : Hemodialysis-induced cardiac injury: determinants and associated outcomes. Clin J Am Soc Nephrol 2009;4:914-920.

114 de los Reyes VA, Fuertinger DH, Kappel F, Meyring-Wosten A, Thijssen S, Kotanko P: A physiologically based model of vascular refilling during ultrafiltration in hemodialysis. J Theor Biol 2016;390:146-155.

115 Kron S, Schneditz D, Leimbach T, Aign S, Kron J: Vascular refilling is independent of volume overload in hemodialysis with moderate ultrafiltration requirements. Hemodial Int 2016;20:484-491.

116 Reddan DN, Szczech LA, Hasselblad V, Lowrie EG, Lindsay RM, Himmelfarb J, et al: Intradialytic blood volume monitoring in ambulatory hemodialysis patients: a randomized trial. J Am Soc Nephrol 2005;16:2162-2169.

117 Maduell F, Arias M, Masso E, Fontsere N, Carrera M, Vera M, et al: Sensitivity of blood volume monitoring for fluid status assessment in hemodialysis patients. Blood Purif 2013;35:202-208

118 Krepel HP, Nette RW, Akcahuseyin E, Weimar W, Zietse R: Variability of relative blood volume during haemodialysis. Nephrol Dial Transplant 2000;15:673-679.

119 Andrulli S, Colzani S, Mascia F, Lucchi L Stipo L, Bigi MC, et al: The role of blood volume reduction in the genesis of intradialytic hypotension. Am J Kidney Dis 2002;40: 1244-1254.

120 Kron J, Schneditz D, Leimbach T, Aign S, Kron S: A simple and feasible method to determine absolute blood volume in hemodialysis patients in clinical practice. Blood $\mathrm{Pu}$ rif 2014;38:180-187.

121 Thijssen S, Kappel F, Kotanko P: Absolute blood volume in hemodialysis patients: why is it relevant, and how to measure it? Blood Purif 2013;35:63-71.

122 Kron S, Schneditz D, Leimbach T, Czerny J, Aign S, Kron J: Determination of the critical absolute blood volume for intradialytic morbid events. Hemodial Int 2016;20:321-326.

123 Onofriescu M, Hogas S, Voroneanu L, Apetrii M, Nistor I, Kanbay M, et al: Bioimpedance-guided fluid management in maintenance hemodialysis: a pilot randomized controlled trial. Am J Kidney Dis 2014; 64:111-118.

124 Earthman C, Traughber D, Dobratz J, Howell W: Bioimpedance spectroscopy for clinical assessment of fluid distribution and body cell mass. Nutr Clin Pract 2007;22:389-405. 
125 Jaffrin MY, Morel H: Body fluid volumes measurements by impedance: a review of bioimpedance spectroscopy (BIS) and bioimpedance analysis (BIA) methods. Med Eng Phys 2008;30:1257-1269.

126 Ward LC: Segmental bioelectrical impedance analysis: an update. Curr Opin Clin Nutr Metab Care 2012;15:424-429.

127 Lukaski HC, Johnson PE, Bolonchuk WW, Lykken GI: Assessment of fat-free mass using bioelectrical impedance measurements of the human body. Am J Clin Nutr 1985;41: 810-817.

128 Peterson JT, et al: "Accuracy of Consumer Grade Bioelectrical Impedance Analysis Devices Compared to Air Displacement Plethysmography: 2105." Med Sci Sports Exerc 2007;39.5:S373.

129 Moissl UM, Wabel P, Chamney PW, Bosaeus I, Levin NW, Bosy-Westphal A, et al: Body fluid volume determination via body composition spectroscopy in health and disease. Physiol Meas 2006;27:921-933.

130 De Lorenzo A, Andreoli A, Matthie J, Withers P: Predicting body cell mass with bioimpedance by using theoretical methods: a technological review. J Appl Physiol (1985) 1997;82:1542-1558.

131 Zhou YL, Liu J, Sun F, Ma LJ, Han B, Shen $\mathrm{Y}$, et al: Calf bioimpedance ratio improves dry weight assessment and blood pressure control in hemodialysis patients. Am J Nephrol 2010;32:109-116.

132 Seibert E, Müller SG, Fries P, Pattmöller J, Kuss O, Heine GH, et al: Calf bioimpedance spectroscopy for determination of dry weight in hemodialysis patients: effects on hypertension and left ventricular hypertrophy. Kidney Blood Press Res 2013;37:58-67.

133 Zhu F, Kuhlmann MK, Kotanko P, Seibert E, Leonard EF, Levin NW: A method for the estimation of hydration state during hemodialysis using a calf bioimpedance technique. Physiol Meas 2008;29:S503S516.

134 Barbosa-Silva MC, Barros AJ: Bioelectrical impedance analysis in clinical practice: a new perspective on its use beyond body composition equations. Curr Opin Clin Nutr Metab Care 2005;8:311-317.

135 Kyle UG, Bosaeus I, De Lorenzo AD, Deurenberg P, Elia M, Manuel Gomez J, et al: Bioelectrical impedance analysis-part II: utilization in clinical practice. Clin Nutr 2004;23: 1430-1453.

136 Tsai YC, Chiu YW, Tsai JC, Kuo HT, Hung CC, Hwang SJ, et al: Association of fluid overload with cardiovascular morbidity and all-cause mortality in stages 4 and 5 CKD. Clin J Am Soc Nephrol 2015; 10:39-46.

137 Oei EL, Fan SL: Practical aspects of volume control in chronic kidney disease using whole body bioimpedance. Blood Purif 2015;39:32-36.

138 Chamney PW, Kramer M, Rode C, Kleinekofort W, Wizemann V: A new technique for establishing dry weight in hemodialysis patients via whole body bioimpedance. Kidney Int 2002;61:2250-2258.

139 Chazot C, Wabel P, Chamney P, Moissl U, Wieskotten S, Wizemann V: Importance of normohydration for the long-term survival of haemodialysis patients. Nephrol Dial Transplant 2012;27:2404-2410.

140 O'Lone EL, Visser A, Finney H, Fan SL: Clinical significance of multi-frequency bioimpedance spectroscopy in peritoneal dialysis patients: independent predictor of patient survival. Nephrol Dial Transplant 2014;29:1430-1437.

141 Wabel P, Chamney P, Moissl U, Jirka T: Importance of whole-body bioimpedance spectroscopy for the management of fluid balance. Blood Purif 2009;27:75-80.

142 Dekker MJ, Marcelli D, Canaud BJ, Carioni P, Wang Y, Grassmann A, et al: Impact of fluid status and inflammation and their interaction on survival: a study in an international hemodialysis patient cohort. Kidney Int 2017;91:1214-1223.

143 Raimann JG, Zhu F, Wang J, Thijssen S, Kuhlmann MK, Kotanko P, et al: Comparison of fluid volume estimates in chronic hemodialysis patients by bioimpedance, direct isotopic, and dilution methods. Kidney Int 2014;85:898-908.

144 Marcelli D, Usvyat LA, Kotanko P, Bayh I, Canaud B, Etter M, et al: Body composition and survival in dialysis patients: results from an international cohort study. Clin J Am Soc Nephrol 2015;10:1192-1200.

145 Arroyo D, Panizo N, Abad S, Vega A, Rincon $\mathrm{A}$, de Jose AP, et al: Intraperitoneal fluid overestimates hydration status assessment by bioimpedance spectroscopy. Perit Dial Int 2015;35:85-89.

146 Davies SJ, Davenport A: The role of bioimpedance and biomarkers in helping to aid clinical decision-making of volume assessments in dialysis patients. Kidney Int 2014; 86:489-496.

147 Tangvoraphonkchai K, Davenport A: Do bioimpedance measurements of over-hydration accurately reflect post-haemodialysis weight changes? Nephron 2016;133:247-252.

148 Siriopol I, Siriopol D, Voroneanu L, Covic A: Predictive abilities of baseline measurements of fluid overload, assessed by bioimpedance spectroscopy and serum $\mathrm{N}$-terminal pro-B-type natriuretic peptide, for mortality in hemodialysis patients. Arch Med Sci 2017;13:1121-1129.

149 Voroneanu L, Cusai C, Hogas S, Ardeleanu $\mathrm{S}$, Onofriescu M, Nistor I, et al: The relationship between chronic volume overload and elevated blood pressure in hemodialysis patients: use of bioimpedance provides a different perspective from echocardiography and biomarker methodologies. Int Urol Nephrol 2010;42:789-797.

150 Ozdogan O, Kayikcioglu M, Asci G, Ozkahya M, Toz H, Sezis M, et al: Left atrial vol- ume predicts mortality in low-risk dialysis population on long-term low-salt diet. Am Heart J 2010;159:1089-1094.

151 Mostafa G, Kumar M, Schlotthauer J, Murray MJ: The utility of hemodynamic measurements acquired by pulmonary artery catheterization. Am J Surg 1998;175:293296.

152 Marik PE, Cavallazzi R: Does the central venous pressure predict fluid responsiveness? An updated meta-analysis and a plea for some common sense. Crit Care Med 2013; 41:1774-1781.

153 Marik PE, Baram M, Vahid B: Does central venous pressure predict fluid responsiveness? A systematic review of the literature and the tale of seven mares. Chest 2008;134: 172-178.

154 Monnet X, Rienzo M, Osman D, Anguel N, Richard C, Pinsky MR, et al: Esophageal Doppler monitoring predicts fluid responsiveness in critically ill ventilated patients. Intensive Care Med 2005;31:11951201.

155 Elwan MH, Hue J, Green SJ, Eltahan SM, Sims MR, Coats TJ: Thoracic electrical bioimpedance versus suprasternal Doppler in emergency care. Emerg Med Australas 2017; 29:391-393.

156 Light LH: Non-injurious ultrasonic technique for observing flow in the human aorta. Nature 1969;224:1119-1121.

157 Chong SW, Peyton PJ: A meta-analysis of the accuracy and precision of the ultrasonic cardiac output monitor (USCOM). Anaesthesia 2012;67:1266-1271.

158 Oda M, Hokama S, Sugaya K, Hatano T, Ogawa Y: New blood volume monitoring method for hemodialysis: A-V pressure gradient measurement by synchronized onepoint reading. Artif Organs 2004;28:683689.

159 Kim W, Park SK, Kang KP, Lee DH, Kim SY, Jung JM, et al: Changes in whole blood viscosity at low shear rates correlate with intravascular volume changes during hemodialysis. Int J Artif Organs 2012;35: 425-434.

160 Yin Z, Zhou J, Cai S, Wang Z: On-line dynamic measurement of blood viscosity, hematocrit and change of blood volume. Chin J Traumatol 2000;3:102-106.

161 Kyle UG, Bosaeus I, De Lorenzo AD, Deurenberg P, Elia M, Gomez JM, et al: Bioelectrical impedance analysis - part I: review of principles and methods. Clin Nutr 2004;23: 1226-1243.

162 Zhu F, Levin NW: Estimation of body composition and normal fluid status using a calf bioimpedance technique. Blood Purif 2015; 39:25-31.

163 Ribitsch W, Stockinger J, Schneditz D: Bioimpedance-based volume at clinical target weight is contracted in hemodialysis patients with a high body mass index. Clin Nephrol 2012;77:376-382. 